\title{
PRIMENA BLOCKCHAINA U INDUSTRIJI TURIZMA
}

\author{
Nikica Radovićc ${ }^{*}$, \\ Aleksandar Matanović2 \\ Milan Radović3
}

\author{
1 Univerzitet Singidunum, \\ Beograd, Srbija \\ ${ }^{2} \mathrm{ECD}$,
}

Beograd, Srbija

${ }^{3}$ Orlean doo,

Beograd, Srbija
Odgovorno lice:

Nikica Radović

e-pošta:

nradovic@singidunum.ac.rs

\section{Rezime:}

Informaciono komunikacione tehnologije nezaustavljivo napreduju u svom razvoju, a primena pojedinih informaciono tehnoloških rešenja doprinosi unapređenju, razvoju i rastu i u industriji turizma. U ovo radu posvetićemo pažnju objašnjenju pojma Blockchain tehnologije, mogućnostima primene ovog savremenog fenomena, sa fokusom na pregled primene Blockchaina $\mathrm{u}$ industriji turizma.

Ključne reči:

Blockchain, turizam, kriptovalute.

\section{UVOD}

Poslovne aktivnosti u različitim privrednim delatnostima baziraju se na odgovarajućim, relevantnim podacima, a prednosti u efikasnom poslovanju ostvaruju se čuvanjem podataka u tzv. bazama podataka koje čine deo poslovnih informacionih sistema. Baze podataka predstavljaju skup podataka koji je organizovan prema potrebama korisnika informacionih sistema $\mathrm{u}$ kojima se nalaze, $\mathrm{u}$ cilju adekvatne primene istih $\mathrm{u}$ donošenju poslovnih odluka [1].

Prilikom realizacije poslovnih procesa često se može javiti problem u komunikaciji i koordinaciji više učesnika ukoliko ne postoji pouzdan i definisan metod komunikacije. Ovaj problem u praksi poznat je pod nazivom „problem vizantijskih generala“[2]. Problem vizantijskih generala definisan je još davne 1982. godine i ilustruje problem u komunikaciji putem posrednika koji nisu pouzdani. Naime, vizantijski generali opsedaju neprijateljski grad i trebalo bi da se dogovore oko zajedničkog plana akcije, da svi napadnu u isto vreme. Ako neki od generala ne izvrše napad u dogovoreno vreme, veoma je verovatno da napad neće uspeti. Pošto se generali nalaze na različitim lokacijama oko grada, ne mogu se uživo dogovarati, već komuniciraju preko kurira. Sada se javljaju dva potencijalna problema. Prvi problem je ako su neki od generala izdajnici. Oni će namerno sabotirati dogovor i preko svojih kurira slati informacije tako da i među poštenim generalima izazovu konfuziju. Druga situacija je u jednostavnijem scenariju, svi generali su pošteni, ali nisu svi kuriri pošteni. Ukoliko pojednostavimo slučaj i zamislimo da imamo tri generala i svaki general po dva kurira, pri čemu svaki šalje po jednog kurira svakom 
od svojih kolega. U ovom primeru, jedan od kurira prvog generala je izdajnički, on namerno trećem generalu prenosi pogrešnu poruku. Prvi i drugi general misle da je dogovor postignut i kreću u napad. Treći general dobija drugačije poruke od svojih kolega i zbog toga ne napada jer smatra da nije postignut dogovor. Bez jednog krila vojske, koja nije pošla u napad, šanse za uspeh u napadu i pobedu su minimalne. Ovaj problem posebno je izražen u sistemima koji nisu centralizovani i gde je broj učesnika prevelik da bi svako sa svakim direktno komunicirao [3]. Rešenje za prevazilaženje problema u komunikaciju u smislu pouzdanosti u prenosu informacija utvrđeno je formiranjem Blockchain tehnologije.

\section{OSNOVE BLOCKCHAIN TEHNOLOGIJE}

Blockchain je vrsta baze podataka zasnovana na matematičkom algoritmu za distribuciju kriptografskih informacija čija se specifičnost ogleda u njenoj nepromenljivosti tj. u bazu se podaci mogu unositi, ali se ne mogu menjati i uklanjati bez konsenzusa. To je javno dostupan registar promena koje su se desile na mreži od njenog formiranja. Sve promene sastavljaju se i registruju u serijama koje se nazivaju „blokovi“ $i$ dodaju na kraju „lanca“ do tada kreiranih blokova, formirajući bazu podataka koja je zahvaljujući svojoj strukturnoj specifičnosti i procesu formiranja dobila naziv Blockchain (lanac blokova). Vremenski intervali tj. razmaci kreiranja blokova nisu pravilni. Svaki blok sadrži podatke kao što su vremenska oznaka, identitet rudara koji dodaje taj blok u Blockchain, informacije o transakcijama koje se u tom bloku nalaze, kao i heš prethodnog bloka pomoću kojeg se novi blok povezuje u postojeći Blockchain. Zahvaljujući Blockchainu svaki Korisnik ima mogućnost uvida da se neka od aktivnosti u bazi dogodila. Za formiranje Blockchain baza podataka uglavnom se koriste programski jezici JavaScript, C++, Viper, Solidity, Python, Go, ...

Kopije Blockchaina distribuirane su na više računara širom sveta, gde se čuvaju potpune ili delimične kopije podataka u blokovima na tzv. čvorovima (nodovima), a svaki računar koji je uključen u sistem mreže proverava validnost svih unetih podataka, čime potvrđuje sigurnost podataka i onda ih dodaje u svoju bazu. Ova specifičnost Blockchaina naziva se decentralizovanim sistemom upravljanja podacima. Ovo je najsigurniji metod čuvanja informacija umesto do sada primenjivanog držanja informacija u jednoj bazi. Na ovaj način više kopija identičnih podataka čuva se na različitim uređajima na mreži, na različitim lokacijama, jer ne postoji centralni server. Informacije se prenose direktno između korisnika, a specifično je da svaki korisnik može biti direktno povezan samo sa nekoliko drugih korisnika, a to je poznato pod nazivom peer to peer mreža. Ovaj način čuvanja podataka podrazumeva da ako i samo jedna tačka bude oštećena ili izgubljena kopije podataka ostaju sigurno sačuvane na više mesta. U skladu sa tim, ukoliko dođe do izmene podataka bez saglasnosti administratora postoji originalni podatak na više drugih mesta koji ukazuje na prvobitno njegovo stanje tj. onemogućuju se izmene, dodavanja, krivotvorenja i uklanjanja prvobitno kreiranog podatka. Kada je u pitanju primena Blockchaina za kriptovalute kod Bitcoina u mreži ima oko 12.000 računara, kod Ethereuma oko 16.000, dok kod ostalih kriptovaluta učestvuje manji broj računara. Na Slici 1. ilustrovana je procedura prema koracima koja se realizuje u procesima primene Blockchain tehnologije [4].

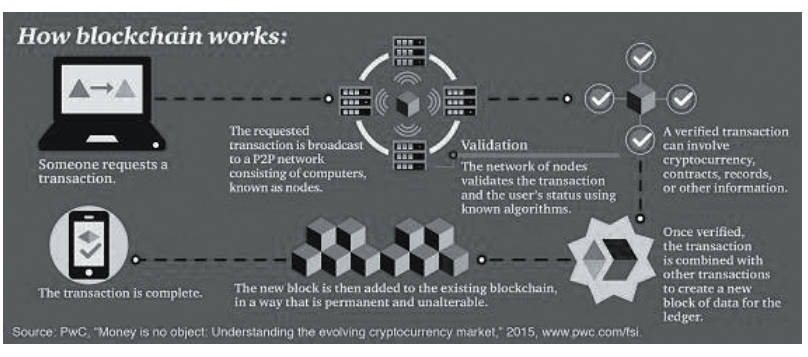

Slika 1. Proces Blockchain tehnologije [4]

Blockchain može biti javni i privatni. Javni Blockchain ima protokol koji upravlja sistemom u formi otvorenog koda, svako mu može pristupiti, svako može da vrši transakcije, svako ima udela u kreiranju blokova i svako može da ima učešća u donošenju odluka, imajući u vidu da svako može da bude čvorište u peer-to-peer mreži, broj tih čvorišta je veoma veliki i samim tim je teže da broj „nepoštenih igrača“ dominira. Ipak, upravo taj veliki broj učesnika može da predstavlja problem, zato što je za bilo koju uspešnu izmenu potrebna saglasnost većina učesnika u mreži, što zbog veličine i broja učesnika može predstavljati problem i vodi u neefikasnost. Ova vrsta Blockchaina je najčešće primenljiva kod projekata kreiranja kriptovaluta. Kao što smo rekli, protokol koji upravlja sistemom je u formi otvorenog koda, pa ko god pristupa bazi može taj kod pregledati, kao i predložiti izmene i dopune tog koda. Ukoliko većina učesnika prihvati predložene promene one postaju sastavni deo protokola. Ovaj slučaj se često dešava kod kriptovaluta, gde se kod malo izmeni i lansira kao nova kriptovaluta, a taj proces se naziva "razdvajanje" (eng. forkovanje). 
Određenim korisnicima Blockchain tehnologije odgovara ovakav način rada, ali ne odgovara im transparentnost i dostupnost bazi podataka, pa su kreirani tzv. privatni Blockchainovi koji u suštini poseduju osobine kao i javni, ali su urađene određene korekcije, te su kod ovog tipa baza podaci vidljivi samo pojedincima koji imaju dozvolu, a koja im je potrebna i za vršenje transakcija, kreiranje blokova, donošenje odluka. Kod ovih baza podataka manji je broj korisnika, pa je lakše postići koncenzus oko svake odluke te se i izmena protokola može lakše i brže implementirati.

Privatni Blockchain ne mora da ima kreiranu i povezanu za start-up kriptovalutu ili token, kao način motivacije "rudara" da održavaju sistem. Sistem Blockchain baza koje su kreirane kao privatne održavaju učesnici projekta kojima je u interesu mogućnost korišćenja istog. Vrlo često privatne Blockchain aplikacije kreira nekoliko kompanija zajedno, kroz određene projekte u funkciji zajedničkog korišćenja. Ako znamo da je broj korisnika mali, ograničen i poznat, to je dobro jer se lakše postiže konsenzus oko donošenja odluka, ali vrlo često je nivo kontrole u malom broju, a to predstavlja manu jer može doći do izražaja neobjektivnost, što dovodi do niza problema. Takođe, informacije koje se nalaze u privatnim Blockchainovima su uglavnom internog karaktera, određenog stepena tajnosti i često mogu biti izazov za hakovanja.

\section{PREGLED PRIMENE BLOCKCHAIN TEHNOLOGIJE}

Imajući u vidu složen sistem ove vrste baze podataka, kao i sigurnost u primeni, Blockchain tehnologija primenjuje se u delatnostima u kojima je poželjno posedovanje jasne, nepromenljive, pregledne evidencije određenih baza podataka u cilju višestruko omogućenog pristupa bazi. Za ovakve potrebe razvijanju se različite aplikacije u formi blok baza podataka kao što su: platforme za kreiranje pametnih ugovora (smart contracts), baze za skladištenje podataka za potrebe finansijskih institucija, zdravstvenih sistema, notara, katastra, egovermenta, logistike (saradnja IBM i MAERSKA), obrazovnog sistema, sistema za glasanja, autorskih prava, on-line prodavnice, društvene mreže, platforme za energetsku efikasnost, u poslovima konsaltinga i revizije ( $\mathrm{PwC}$ primenjuje ovu tehnologiju u reviziji kapitala u partnerstvu sa kompanijom Northern Trust [5]), ali zasigurno najpoznatija uloga Blockchaina je u kreiranju i prenosu kriptovaluta.
Kriptovalute predstavljaju digitalno sredstvo kreirano za potrebe razmene, zasnovano na tehnologiji kriptografije, uz osiguran tok transakcije, kao i kontrolu stvaranja i plasiranja dodatnih jedinica valute, tokena [6]. Kriptovalute, kao proizvod Blockchain tehnologije predstavljaju samo jedan način primene ovog savremenog koncepta digitalnih tehnologija. Pojam Blockchain tehnologije prvi put $\mathrm{u}$ javnosti se pojavljuje 2008. godine, kada se u medijima plasira informacija o novoj vrsti novca. U pitanju je bilo pojavljivanje Bitcoina, kriptovalute koja počiva na Blockchain tehnologiji, a na Slici 2. ilustrovan je princip Blockchaina u funkciji prenosa kriptovaluta [7]. Od 2009. godine, kada su kreirane prve jedinice Bitcoina, do danas plasirano je preko 1000 drugih kriptovaluta od kojih su poznatije Ether, Lightcoin, Bitcoin Cash, NEO.

Izazov primene Blockchain tehnologije implementirani su i na nivou vođenja i planiranja pojedinih sfera državne ekonomije, pa su tako Kanada, Estonija, Tajland, Singapur, Švedska, UAE, Grčka, Slovenija i Japan implementirali projekte primene Blockchain tehnologije u važne segmente koji doprinose razvoju određenih grana privrede pomenutih država.

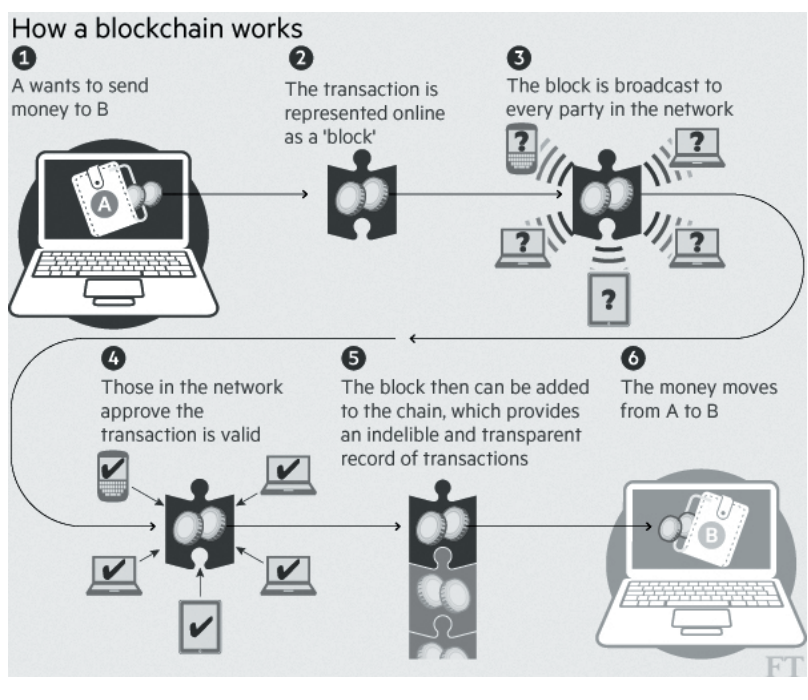

Slika 2. Primena Blockchaina u funkciji kriptovaluta [7]

Primena Blockchaina u raznim industrijama realizuje se kroz kreirane startup-ove koji se baziraju na otvorenim platformama sa jasno definisanim pravilima u procesima, u cilju optimalne saradnje i postizanja određenog benefita.

Kompanija IBM razvila je IBM Blockchain baziran na Hiperledger Fabric platform Linux Foundation i ima kreirane aplikacije za različite delatnosti: bankarstvo, 
finansijski sektor, e-goverment, sektor zdravstva, osiguranja, trgovine, logistike, u prehrambenoj industriji [8].

Ernest\&Young (EY), jedna od vodećih konsultantskih kuća u svetu, podružnica u Italiji i EZLab razvili su aplikaciju Wine Blockchain, na Etherium platformi, koju karakteriše baza podataka koja sadrži dnevnik svih transakcija tj. unosa informacija, tako da svaki učesnik može proveriti ispravnost svakog koraka transakcija [9]. Naime, potrošač može u bilo kom trenutku i mestu prodaje skeniranjem QR koda sa etikete vinske boce da proveri poreklo, organoleptičke karakteristike i celokupni agro-prehrambeni i industrijski lanac sertifikovan od strane proizvođača. Podaci koji su dostupni, a pohranjeni u bazi podataka su veoma detaljni: lokacija vinograda u kojem je gajeno grožđe, vrste vinove loze tj. sorte grožđa, fitosanitarni i poljoprivredni tretmani izvedeni sa svim koracima i proizvodnim metodama, datum branja grožđa, karakteristike rezervoara za fermentaciju, datum flaširanja gotovog vina, serijski broj, PHa vina [9].

Prvi korisnik ove digitalne aplikacije za sertifikaciju proizvodnje i distribucije vina je vinarija Cantina Volpone iz regije Apulije, na jugu Italije, koja primenom najsavremenije tehnologije želi da utiče na transparentnost i garantuje poreklo i kvalitet svog vina po principu "od vinograda do trpeze" [10]. Imajući u vidu razvijen segment vinskog turizma u Italiji, kao specifičnog turističkog proizvoda, ova tehnološka inovacija može da utiče na unapređenje već razvijenih vinskih tura u italijanskim regijama, jer doprinosi povećanju stepena očekivanja i poverenja korisnika usluga. Na Slici 3. [9] ilustrovan je Wine Blockchain prema transakcijama koje se realizuju.

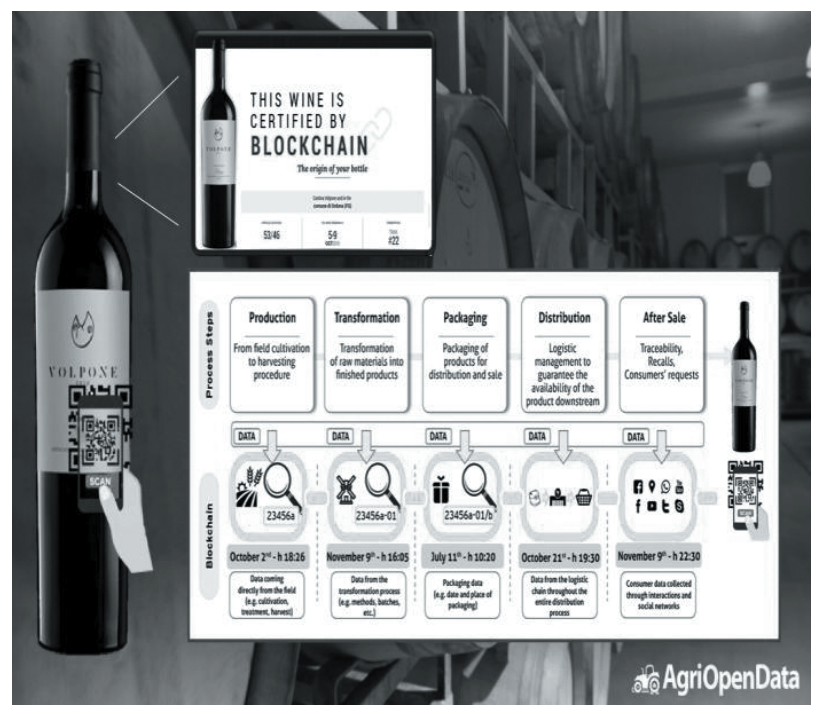

Slika 3. Wine Blockchain kroz faze [9]
EY i kompanija SAP započeli su saradnju u cilju implementacije Blockchain aplikacije i usluge pomoću SAP ${ }^{\circ}$ Leonardo digitalnog inovativnog sistema u poslovanju velikog broja kompanija. EY Ops Chain predstavlja jedno od prvih Blockchain rešenja, dizajnirano za korisnike koji će ga koristiti za pojednostavljivanje upravljanja lancem snabdevanja, a biće integrisano u SAP ${ }^{\circledast}$ Leonardo aplikaciji. Koristeći EY Ops Chain, kompanije će moći da kreiraju digitalne ugovore, da efikasnije formiraju i prate cene, fakturisanja i isplate, da dele inventar i logističke informacije. SAP ${ }^{\circ}$ Leonardo pomaže u pojednostavljivanju inovacija sa novim tehnologijama i uključuje ih u poslovanje kupca sa punom skalabilnošću, a svojom kompleksnošću u mogućnosti je da transformiše i obrađuje veliki broj podataka ERPa i CRMa u funkciji pojednostavljanja složenih transakcija u digitalnoj ekonomiji [11] .

PricewaterhouseCoopers $(\mathrm{PwC})$ primenjuje Blockchain tehnologiju u svom poslovanju, pa osim već pomenute saradnje u procenama kapitala na prostorima SAD, PwC je u Kini u maju 2016. godine započeo saradnju sa start-up kompanijom BitSE i blisko sarađuju sa brojnim preduzećima, lokalnim finansijskim institucijama i međunarodnim brendovima kako bi istražili i razvili planove za implementaciju Blockchain aplikacija baza podataka i unapredili poslovanje [12].

Blockchain aplikacije kreirane su i primenjuju se uspešno u oblasti osiguranja i upravljanja imovinom u poslovanju svetski poznatih kompanija kao što su: Allianz, Zurich Insurance Group, Aegon i druge.

\section{INDUSTRIJA TURIZMA}

Prema podacima UNWTO [13] industrija turizma sa učešćem od $10 \%$ u svetskom BDP i ostvarenim prihodima u 2017. godini u visini od 1,322 biliona US\$, predstavlja najbrže rastuću privrednu delatnost u svetu i ključni pokretač razvoja mnogih regiona. Pololikashvili, generalni sekretar UNWTO, ističe značaj turizma sa aspekta uticaja na prosperitet zajednica širom sveta, ukazujući na to da je svaki deseti stanovnik sveta angažovan u nekom segmentu industrije turizma, kao i da niz potreba za aktivnostima u turističkoj industriji utiču na zapošljavanje lokalnog stanovništva [13]. Sve to implicira da je turizam na trećem mestu delatnosti na nivou svetskih privrednih kretanja.

Industrija turizma predstavlja kompleksnu zajednicu privrednih delatnosti koje sinergetskim poslovanjem doprinose realizaciji putovanja i doživljaja korisnika 
usluga. Obuhvaćene su delatnosti kompanija koje posluju u oblasti saobraćaja, organizacije i prodaje putovanja (organizatori putovanja i turističke agencije), smeštajnih kapaciteta (hoteli, hosteli, renta stanovi i slično), ugostiteljskih usluga (restorani, kafići, pivnice, fast food kompanije), lokalna transportna preduzeća (autobuska preduzeća, taksi udruženja, renta kar kompanije, gradska saobraćajna preduzeća), preduzeća i pojedinci koje se bave izradom i prodajom suvenira, trgovinske kompanije i niz drugih kompanija od čijeg poslovanja zavisi autentičnost $i$ atraktivnost destinacije uz prirodne i antropogene resurse koji su najčešće fokus promocije jedne turističke destinacije.

U savremenom poslovanju u turizmu i hotelijerstvu primena informaciono komunikacionih tehnologija (IKT) je neophodna u cilju unapređenja poslovnih procesa, efektivnosti i efikasnosti, kao i ostvarenja kvaliteta u pružanju usluga. Danas, IKT napreduju i usavršavaju se velikom brzinom, pa pojedina tehnička rešenja vrlo brzo zastarevaju tj. postaju "prevaziđena" (npr. pojedini softveri, faks uređaji, telefonska rezervacija i sl.), pa primena Blockchain tehnologije sa više aspekata predstavlja optimalno rešenje.

\section{PRIMENA BLOCKCHAIN APLIKACIJA U INDUSTRIJI TURIZMA}

Finansijsko poslovanje u industriji turizma zasniva se na prenosu novčanih sredstava po osnovu aktivnosti koje se odnose na plaćanja realizovanih turističkih usluga - karata za prevoz turista, usluga smeštaja i ishrane, obilaska destinacija, kupovina suvenira, drugim rečima svih aktivnosti koje najčešće obuhvataju proces putovanja.

Plaćanja u turističkom sektoru realizuju se u gotovinskom i bezgotovinskom načinu plaćanja, u svim stranim valutama koje su prisutne na bankarskom tržištu. Bezgotovinsko plaćanje realizuje se u formi plaćanja platnim karticama ili putem elektronskog bankarstva. Novi segment primene bezgotovinskog plaćanja $\mathrm{u}$ industriji turizma je implementacija digitalnog novca, tzv. kriptovaluta. S tim u vezi, na turističkom tržištu izdvojile su se pojedine onlajn turističke agencije koje prodaju aranžmane, avio karte, usluge rent-a-kara i osiguranja u standardnim valutama, ali formirale su cene i organizovala su procese plaćanja korisnika usluga u Bitconima, a to su Destinia [14], PointsHound [15], dok onlajn turistička agencija BtcTrip ima formirane cene samo u Bitcoinima [16].
Osim pojave kriptovaluta, Blockchain u industriji turizma učestvuje i u vidu kreiranih projekata tzv. startupova, gde turističke kompanije ili organizacije osmišljavaju poslovnu ideju i izrađuju studije, a potom plasiraju sopstvenu kriptovalutu u formi tokena, koji figuriraju kao akcije na tržištu, čijom trgovinom ili angažovanjem zainteresovanih strana dolazi do priliva novčanih sredstava. To su tzv. decentralizovani poslovni modeli, a u svetu turizma interesantni primeri su projekti WebJet, Concierge.io i Winding Tree.

WebJet je australijska onlajn turistička agencija koja je implementirala Blockchain tehnologiju u saradnji sa Microsoft korporacijom koristeći Microsoftovu Azure platformu u cilju osavremenjivanja i unapređenja poslovnih aktivnosti u vezi prodaje smeštajnih kapaciteta [17].

Concierge.io je decentralizovana platforma za onlajn prodaju turističkih aranžmana u Vijetnamu, čije poslovanje se zasniva na NEO Blockchain platformi. Kreiran je CGE token koji će prema planu startovati sa trgovanjem u četiri nedelje, od 31. 3. 2018. do 28. 4. 2018. godine. Turistički aranžmani se na sajtu za sada prodaju u US dolarima, ali formirane su cene izražene u CGE tokenima [18].

Winding Tree je decentralizovana distribuirana platforma u sferi kreiranja putovanja. Poslovanje je kreirano na Etherium platformi kao potpuno automatsko rešenje, integrišući se direktno sa rezervacionim sistemima organizatora putovanja. Naime, povezuje snabdevače (hotele, avio-kompanije itd.) i prodavce (putničke agencije). Dobavljači postavljaju informacije o ceni i dostupnosti u bazu podataka, gde ih prodavci mogu pronaći, bez ljudske intervencije. Kreiran je Lif token za potrebe korišćenja turističkih preduzeća da distribuiraju inventor i vrše transakcije bez posrednika. Vidljiva i uspešna saradnja započela je sa Air New Zealand i Lufthansom [19]. Takođe, ovu platformu implementirala je karipska ostrvska država Aruba u cilju povezivanja i integrisanja brojnih malih hotela, kako bi bili vidljiviji, a sigurniji u poslovanju [20].

Uprava grčkog ostrva Agistri, koje se nalazi nedaleko od Pireja, implemetirala je projekat Blockchaina, u formi novog monetarnog ekosistema, kroz plasiranje Nautiluscoina, kriptovalute koja će im služiti kao moneta u daljoj realizaciji projekta [21]. Zvaničnici Ruske Federacije, šef ruske federalne agencije za turizam Oleg Safonov na turističkom forumu u Kazanu, u novembru prošle godine, naveo je da u Rusiji postoje ozbiljni planovi implementacije ovog savremenog tehnološkog procesa u razvoju turizma [22]. 
TUI Group nemačka kompanija koja se ubraja u lidere u prodaji turističkih aranžmana implementirala je Blockchain tehnologiju u svom poslovanju u partnerstvu sa IBM kompanijom kroz projekat BedSwap. Za potrebe praćenja internog poslovanja i evidencije smeštajnih kapaciteta u realnom vremenu TUI Group koristi Etherium Blockchain platformu. Na ovaj način formirana je globalna baza podataka smeštajnih kapaciteta uz povezanost sa rezervacionim sistemom i platnim sistemom, pa će poslovanje biti sigurnije za korisnike usluga jer će biti onemogućeno višestruko rezervisanje i naplata smeštaja. Osim toga implementacija Blockchaina je i deo strategije ignorisanja poslovanja monopolista na tržištu smeštajnih kapaciteta kao što su Booking.com, Expedia.com i Airbnb.com [23].

Blockchain tehnologija u turizmu najviše se primenjuje kreiranjem određenih baza podataka putem kojih korisnici turističkih usluga mogu da realizuju kupovinu avionskih karata, rezervaciju i plaćanje usluga smeštaja, hrane i pića, ostavljanje komentara bez mogućnosti izmena i drugo. Ovaj način poslovanja u industriji turizma u svetu zaživeo je i realizuje se uporedo sa razvojem i implementacijom Blockchain tehnologije u svim globalnim privrednim tokovima.

Dakle, $\mathrm{u}$ industriji putovanja primena Blockchaina realizuje se sa više aspekata:

- implementacijom novog načina poslovanja u eturističkim agencijama uz inoviranje naplaćivanja usluga primenom Blockchaina i naplate realizacije usluga u Bitconima ili nekim drugim kriptovalutama

- uvođenjem mogućnosti kao sredstva plaćanja u avio saobraćaju

- u cilju bezbednosti i zaštite podataka korisnika usluga, utvrđivanju identiteta putnika, unapređenju praćenja prtljaga

- sa ciljem unapređenja programa lojalnosti korisnika usluga, kroz projekat ,istorije gosta“

- primenom pametnih ugovora.

\section{ZAKLJUČNA RAZMATRANJA}

Danas su u svetu, podeljena mišljenja, stavovi i poverenje u odnosu na koncept Blockchain tehnologije i kriptovaluta, kao najpoznatijeg segmenta primene. Ipak, trebalo bi navesti prednosti primene Blockchaina $\mathrm{u}$ industriji turizma:
- poboljšanje kvaliteta turističkih usluga

- poboljšanje tačnosti i sigurnosti informacija (npr. nemogućnost naknadnog korigovanja unetih komentara gostiju)

- mogućnost direktnog kontakta sa pružaocima usluga što za rezultat ima smanjenje troškova i nepostojanje provizija tj. pristupačnije cene. Monopolistički pozicionirane onlajn turističke agencije Booking.com, Expedia.com partnerima naplaćuju od $15 \%$ do $45 \%$ provizije kao naknadu za prodaju kapaciteta, a često naplaćuju i krajnjem korisniku oko 3\% za usluge transakcije. Upravo primenom Blockchain tehnologije i pametnih ugovora prevazilaze se visoki troškovi i provizije.

Imajući u vidu ideju internacionalizacije u turističkom poslovanju primena kriptovaluta i Blockchaina samo bi olakšala poslovanje prodavcima, a korisnicima usluga satisfakciju i veće poverenje, sa smanjenom mogućnošću zloupotrebe u poslovnim aktivnostima, uz besplatne transakcije, bez bankarskih naknada što vodi smanjenju troškova poslovanja. Zahvaljujući primeni Blockchaina u industriji turizma omogućena je transparentna, adekvatna, efikasna komunikacija sa korisnicima usluga, a u cilju povezivanja putnika sa određenim turističkim regijama, destinacijama i kompanijama koje posluju u okviru njih.

\section{LITERATURA}

[1] M. Veinović, G. Šimić, A. Jevremović \& I. Franc, "Baze podataka", Beograd: Univerzitet Singidunum, 2013, str. 15.

[2] L. Lamport, R. Shostak \& M. Pease, “The Byzantine Generals Problem", ACM Transactions on Programming Languages and Systems, Vol. 4, No. 3, July 1982

[3] A. Matanović, "Uvod u bitkoin i kriptovalute Uvod u blockchain", Beograd: Univerzitet Metropolitan, 2017, str. 6.

[4] https://www.pwc.com/us/en/industries/financialservices/fintech/bitcoin-blockchain-cryptocurrency.html

[5] https://coinjournal.net/northern-trust-pwc-blockchain/

[6] U.Chohan, "Cryptocurrencies: A Brief Thematic Review”, August 4, 2017., Available at SSRN: https://ssrn.com/abstract $=3024330$

[7] www.weforum.org/agenda/2016/06/blockchainexplained-simply/

[8] www.ibm.com/blockchain/ 
[9] http://www.ezlab.it/portfolio/wine-blockchain/

[10] https://agrichain.cantinavolpone.com/a/0x160564d 346f6e9fb3d93c034f207ecf9791b7739/0x1

[11] http://www.ey.com/gl/en/newsroom

[12] https://www.coindesk.com/press-releases/pwc-announces-strategic-alliance-bitse/

[13] UNWTO Tourism Highlights 2018, www.unwto. org

[14] www.destinia.com/m/bitcoins

[15] https://www.coindesk.com/benefits-bitcoin-international-travel/

[16] www.btctrip.com

[17] https://news.microsoft.com/en-au/2016/11/08/ webjet-and-microsoft-build-first-of-a-kind-travelindustry-blockchain-solution/
[18] www.concierge.io

[19] www.windingtree.com

[20] www.cointelegrapf.com

[21] B. Kelly, "Greek island agrees to test digital currency commentary", preuzeto sa www.cnbc.com. 25.01.2018., greek-island-agrees-to-test-digitalcurrency-commentary.html, 2015.

[22] https://www.coindesk.com/russian-official-blockchain-will-seriously-change-tourism-industry/

[23] https://www.tuigroup.com/en-en/media/stories/special-themed-section/digitalisationand-innovation/2017-06-22-tui-to-use-blockchain-opportunities 